\title{
Characterization of Isotactic Polypropylene and Hydrogenated Oligocyclopentadiene Blends
}

\author{
Z. I. Ali, H. M. Said and H. H. Saleh
}

Radiation Chemistry Dept., National Centre for Radiation Research and Technology (NCRRT), P. O. Box; 29 Nasr City, Egypt.

\begin{abstract}
7 HE MECHANICAL, dynamic thermal mechanical, thermal, and morphological properties of pre-irradiated isotactic polypropylene (iPP) and pre-irradiated hydrogenated oligocyclopentadiene (HOCP) blends were studied. Melting points $\left(\mathrm{T}_{\mathrm{m}}\right)$, heat of fusion $\left(\Delta \mathrm{H}_{\mathrm{f}}\right)$ and overall crystallinity of iPP/ HOCP blends decreased as a result of addition of preirradiated HOCP resin. Incorporation of HOCP resin in iPP matrix exhibited better mechanical properties, (tensile stress and elongation at break) as compared with blank iPP sample. The dynamic thermal mechanical data showed that the addition of HOCP resin slightly decreased the storage modulus from $-100{ }^{\circ} \mathrm{C}$ up to $0.0{ }^{\circ} \mathrm{C}$ and then after there is an abrupt change was observed. Also, the modulus loss curves illustrated the presence of a single peak indicating a good dispersity of compatible systems. Morphological analysis of iPP/ HOCP blends investigated the presence of a homogenous phase in the amorphous regions of the polymeric system. Modification of iPP matrix in the presence of HOCP resin with different molecular wt should be allow a distortion of the crystalline structure and therefore the HOCP resin will be partially dissolved (compatible) in the amorphous phase and partially trapped in iPP crystal phase.
\end{abstract}

Keywords: Physicochemical properties, isotactic polypropylene, hydrogenated oligocyclopentadiene, radiation.

iPP is one of the most diffuse semi-crystalline polymer widely used in several sectors, as it offers interesting combinations of good mechanical performance, heat resistance, fabrication flexibility, easy processing, large applicability and low cost. In particular, some rubbers have been added into iPP matrix to improve its impact strength at room temperature or below, or to study the 
influence that elastomers, such as polyisobutylene or ethylene-propylene copolymer, on its crystalline behaviour and mechanical properties. A different type of additive is used to enhance iPP modulus; this is a non-crystalline HOCP resin, where glass transition temperature $\left(\mathrm{T}_{\mathrm{g}}\right)$ is higher than that of iPP. Furthermore, the HOCP resin is compatible with iPP matrix in the melt as well as in the amorphous regions of the polyolefin, in the composition range from 0.0 to 50 wt \% of HOCP content (Astartta et al., 1993).

A great deal interest and numerous studies have been devoted to the blending of iPP with HOCP resins because of the particular enhancement of some technological properties of iPP after blending. The scientific interest in these blends has increased progressively, and some experimental results indicated a number of peculiar yet interesting properties (Sliverstre et al., 1999). Several studies are oriented to decrease the diffusion of gases through the polymer walls. One of the approaches consists in the addition of a certain amount of a second component to the iPP polymer. iPP polymer based film with reduced permeability to oxygen was obtained by addition of a petroleum derived resin HOCP. Increasing HOCP content lowers oxygen permeability and diffusivity through the polymeric films and increases the glass transition temperature of the polymeric blends (Triolo et al., 2000).

The crystallization and thermal behaviour of iPP/ HOCP blends have been studied by several authors. It was found that the spherulite growth rate, the overall crystallization rate as well as the equilibrium melting point of iPP were drastically depressed by the addition of HOCP (Bonfatti et al., 1993). In general, both the amorphous and crystalline phases contribute to the final properties of polymer blends. The chemical, mechanical, physical and electrical properties of iPP can be improved by blending it with proper plasticizers, additives, modifiers, etc. Films of iPP blended with HOCP resin are used in the packaging industry owing to their reduced permeability to oxygen and flavouring compared with iPP films (Bonfatti et al., 1993).

The aim of the present work is to gain more insight, as a function of irradiation of blend components and the influence of molecular wt of HOCP resin, about the thermal, mechanical, dynamic mechanical, morphological, compatibility, and phase structural variation of iPP and its iPP/HOCP blends.

Egypt. J. Rad. Sci. Applic., Vol. 24, No. 2 (2011) 


\section{Experimental}

iPP, average molecular wt $\left(\mathrm{M}_{\mathrm{w}} \cong 3.0 \times 10^{5}\right)$, melt flow index $(\mathrm{MFI}) \cong 2.6$ $\mathrm{g} / 10$ minute and density of about $0.9 \mathrm{~g} / \mathrm{cm}^{3}$. Commercial synthetic HOCP with different molecular wt (produced by Escorez Esso chemical Co.). The commercial HOCP resin used here is a mixture of 1,4 and 1,2 isomers of the following structures $\mathrm{A}$ and $\mathrm{B}$, respectively. The structures and the physical properties of HOCP resins are presented in scheme 1 and Table 1.

TABLE 1. Physical properties of HOCP resins.

\begin{tabular}{|c|c|c|c|c|c|}
\hline \multirow{2}{*}{ HOCP codes } & \multicolumn{3}{|c|}{ Molecular wt distribution $(\mathrm{g} / \mathrm{mol})$} & \multirow{2}{*}{} & \multirow{2}{*}{$\mathbf{M}_{\mathbf{w}} / \mathbf{M}_{\mathbf{n}}$} \\
\cline { 2 - 4 } & $\mathbf{M}_{\mathbf{n}}$ & $\mathbf{M}_{\mathbf{m}},{ }^{\mathbf{0}} \mathbf{C}$ \\
\hline HOCP 1 & 630 & 1300 & 2100 & 2.06 & 100 \\
HOCP 2 & 260 & 480 & 600 & 1.85 & 86 \\
HOCP 3 & 250 & 360 & 580 & 1.44 & 82 \\
\hline
\end{tabular}

$M_{n}$ Number average molecular wt.

$M_{w}$ wt average molecular wt.

$\mathrm{M}_{\mathrm{z}}$ z-average molecular wt.

A

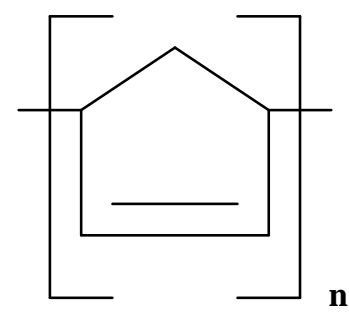

1-4 structure
B

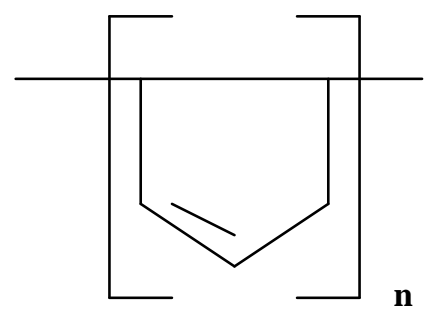

1-2 structure

Scheme 1. Structure of HOCP resin.

The raw materials (iPP and HOCP) were activated by electron beam irradiation before mixing processing. Irradiation ( $20 \mathrm{kGy})$ was carried out at ambient temperature in air by electron beam accelerator, (energy of electron 1.5 $\mathrm{MeV}, 25 \mathrm{~kW}$ electron beam accelerator and installed at NCRRT, Egypt.. Blends of iPP/ HOCP (80/20 wt\%) were prepared by mixing both preirradiated iPP and HOCP components in a laboratory Brabender twin-screw extruder Plastic order PL2100, Germany at temperature of about $200{ }^{\circ} \mathrm{C}$ with a mixing rate of $60 \mathrm{rpm}$ for five minutes. The hot melt polymer mixture was immediately transferred from the mixer to an open roll-mill to sheet. The polymeric sheets of $1.0 \mathrm{~mm}$ thickness were obtained by pressing under hot press at $200{ }^{\circ} \mathrm{C}$ for $5 \min (2.0$

Egypt. J. Rad. Sci. Applic., Vol. 24, No. 2 (2011) 
minutes preheating and 3 minutes at $15 \mathrm{MPa}$ ). The molded polymeric sheets were then immediately transferred to water-cooled press at the same pressure.

The thermal properties of iPP and iPP/ HOCP (80/20 wt $\%$ ) blends were analyzed with DSC (Perkin-Elmer DSC-7); nearly $10 \mathrm{mg}$ of each sample was heated from 25 up to $200{ }^{\circ} \mathrm{C}$ at heating rate of $10{ }^{\circ} \mathrm{C} /$ minute in atmosphere of nitrogen. The percentage crystaillinty of the blend $\left(\mathrm{X}_{\mathrm{c}}\right)$ was calculated from the following expression:

$$
X c(\text { blend })=\frac{\Delta H f(\text { blend })}{\Delta H o(i P P)} \times 100
$$

where, $\Delta \mathrm{H}_{\mathrm{f}}$ and $\Delta \mathrm{H}_{\mathrm{o}}$ are the heat of fusion for blend and $100 \%$ crystalline iPP that was taken to be $209 \mathrm{~J} / \mathrm{g}$ (Ivanov et al., 2001).

The polymeric samples were tested in the form of dumbbell shape of initial dimensions of $40 \mathrm{~mm}$ in length and $4.0 \mathrm{~mm}$ in width at the working area. The investigated samples were tested at ambient temperature according to the ASTM specification using tension machine $(50 \mathrm{~mm} / \mathrm{min}$ ) type M-10 made by Hungta Instrument LTD, Taiwan. The mechanical properties, \{tensile strength at peak $\left(\mathrm{TS}_{\mathrm{p}}\right)$, elongation at peak $\left(\mathrm{E}_{\mathrm{p}}\right)$, tensile strength at break $\left(\mathrm{TS}_{\mathrm{b}}\right)$ and elongation at break $\left(\mathrm{E}_{\mathrm{b}}\right)$, were determined.

Dynamic mechanical analysis (DMA) measurements (mechanical loss $(\tan \delta)$, storage modulus $\left(E^{\prime}\right)$ and loss modulus $\left(E^{\prime \prime}\right)$ were carried out on a dynamic mechanical analyzer (Rheometric Scientific, DMTA MK III). The experiment was performed at a constant frequency of $1.0 \mathrm{~Hz}$ as a function of temperature varied within the range from $-100{ }^{\circ} \mathrm{C}$ up to $+150{ }^{\circ} \mathrm{C}$, (heating rate $10^{\circ} \mathrm{C} /$ min under nitrogen atmosphere). The experiment was performed in tensile mode using samples with dimensions of $40 \times 20 \times 10 \mathrm{~mm}$. The applied strain was in the range of $8-15 \%$ of original sample, which was determined to be in the linear viscoelastic region.

The morphology of the fracture surface of iPP and its iPP/HOCP blends was examined by scanning electron microscope (SEM) (JSM-5400 instrument by Jeol, Japan). The investigated samples were kept for one hour in liquid nitrogen prior to fracture. A sputter coater was used to pre-coat conductive gold onto the fracture surface before observing the microstructure at $15 \mathrm{kV}$.

Egypt. J. Rad. Sci. Applic., Vol. 24, No. 2 (2011) 


\section{Results and Discussion}

\section{Thermal characterization of $\mathrm{PPP}$ and $\mathrm{PP} / \mathrm{HOCP}$ blends}

DSC thermograms of blank iPP and iPP/HOCP (80/20 wt\%) blends are presented in Figure 1. All the obtained thermograms showed the characteristic melting behaviour in the temperature range $158-162{ }^{\circ} \mathrm{C}$. The blank iPP sample exhibited a melting point with onset and melting temperatures at about $155{ }^{\circ} \mathrm{C}$ and $162{ }^{\circ} \mathrm{C}$, respectively. Slight shifts toward lower temperature in the melting temperature maximum peak of iPP/ HOCP blends were noticed due to the loading of iPP with different molecular weight HOCP resins. Also, it can be clearly seen that all iPP/ HOCP blends showed a single melting point at different temperatures indicating that all the blends form a homogenous amorphous phase (i.e., compatible system). This finding may be due to incorporation of pre-irradiated HOCP resin which retards the crystallization of pre-irradiated iPP matrix during mixing process (Pluta et al., 2000).

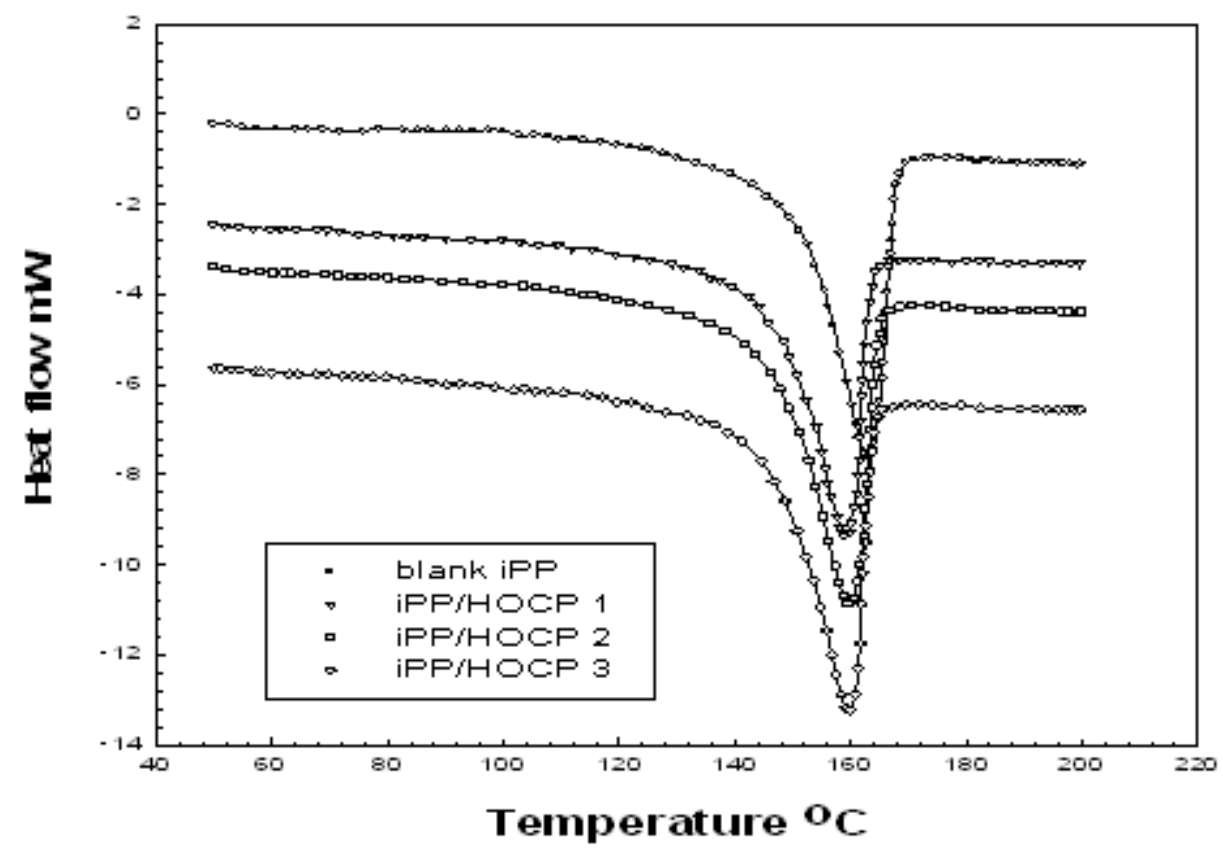

Fig. 1. Differential scanning calorimetry of blank iPP and iPP/ HOCP (80/20 wt \%) samples.

Table 2. shows the different calorimetric parameters, the calculated crystallinity content referred to iPP $\left(\mathrm{X}_{\mathrm{c}}\right)_{\mathrm{a}}$, the overall crystallinity of the blend Egypt. J. Rad. Sci. Applic., Vol. 24, No. 2 (2011) 
$\left(\mathrm{X}_{\mathrm{c}}\right)_{\mathrm{b}}$ and the total amorphous content, $\left(\mathrm{X}_{\mathrm{a}}\right)$ for iPP and iPP/ HOCP $(80 / 20 \mathrm{wt} \%)$ samples. As shown in Table 2. $\Delta \mathrm{H}_{\mathrm{f}}$ decreased from 96.2 down to $75.6 \mathrm{~J} / \mathrm{g}$ and the calculated crystallinity either iPP or iPP/ HOCP blends decreased due to the blending of iPP with different molecular wt HOCP resins.

Also, it can be observed that the calculated crystallinity percents of iPP/ HOCP blends $\left(\mathrm{X}_{\mathrm{c}}\right)_{\mathrm{a}}$ and $\left(\mathrm{X}_{\mathrm{c}}\right)_{\mathrm{b}}$ were lower than that for blank iPP sample. The decrease in the calculated crystallinity can be attributed to the influence of HOCP resin as a reinforcing nucleating agent and also as a heat promoter in the blend. On the other hand, the calculated total amorphous content $\left(\mathrm{X}_{\mathrm{a}}\right)$ exhibited an opposite behaviour showing an increment trend. The decrease of all the reported calorimetric parameters reflected the effect of the change in the molecular wt distribution values of HOCP resins (Slivestre and Cimmino, 2003).

TABLE 2. $\mathrm{T}_{\mathrm{m}},{ }^{\circ} \mathrm{C}, \mathrm{H}_{\mathrm{f}}, \mathrm{J} / \mathrm{g}$, overall crystallinity percent of iPP/ HOCP blends $\left\{\left(\mathbf{X}_{\mathrm{c}}\right)_{\mathrm{b}}\right\}$, crystallinity percent of iPP component $\left\{\left(\mathbf{X}_{\mathrm{c}}\right)_{\mathrm{a}}\right\}$ and total amorphous percent $\left(X_{a}\right)$ of iPP and $\mathrm{iPP} / \mathrm{HOCP}(80 / 20 \mathrm{wt} \%)$ blends.

\begin{tabular}{|c|c|c|c|c|c|c|c|c|}
\hline $\begin{array}{c}\text { Sample } \\
\text { codes }\end{array}$ & $\begin{array}{c}\text { Sample } \\
\text { composition }\end{array}$ & $\begin{array}{c}\mathbf{H O C P} \\
\text { wt } \%\end{array}$ & $\begin{array}{c}\text { Onset temp } \\
{ }^{\circ} \mathrm{C}\end{array}$ & $\begin{array}{c}\mathbf{T}_{\mathbf{m}} \\
{ }^{\circ} \mathrm{C}\end{array}$ & $\begin{array}{c}\Delta \mathbf{H}_{\mathbf{f}} \\
\mathrm{J} / \mathrm{g}\end{array}$ & $\begin{array}{c}\mathbf{( X}_{\mathbf{c}} \mathbf{c}_{\mathbf{a}} \\
\mathbf{i P P}\end{array}$ & $\begin{array}{c}\left(\mathbf{X}_{\mathbf{c}} \mathbf{s}_{\mathbf{b}}\right. \\
\text { blend }\end{array}$ & $\left(\mathbf{X}_{\mathbf{a}}\right)$ \\
\hline $\mathbf{1}$ & blank iPP & 0.0 & 155 & 162 & 96.2 & 46.0 & 46.0 & 54.07 \\
$\mathbf{2}$ & iPP/HOCP 1 & 80 & 151 & 160 & 79.7 & 47.6 & 38.1 & 61.97 \\
$\mathbf{3}$ & iPP/HOCP 2 & 80 & 150 & 159 & 77.8 & 46.5 & 37.2 & 62.8 \\
$\mathbf{4}$ & iPP/HOCP 3 & 80 & 146 & 158 & 75.6 & 45.2 & 36.2 & 63.8 \\
\hline
\end{tabular}

\section{Mechanical properties}

The obtained results demonstrated that the mechanical properties of iPP/HOCP blends generally are enhanced due to the addition of HOCP resin (see Table 3). In addition, the mechanical properties for iPP/HOCP blends increased as a result of decreasing the molecular wt of HOCP resins.

TABLE 3. Mechanical parameters of iPP and iPP/ HOCP (80/ $20 \mathrm{wt} \%)$ samples.

\begin{tabular}{|c|c|c|c|c|}
\hline $\begin{array}{c}\text { Sample } \\
\text { code }\end{array}$ & $\begin{array}{c}\text { Stress at yield } \\
\mathrm{MPa}\end{array}$ & $\begin{array}{c}\text { Elongation \% } \\
\text { at yield }\end{array}$ & $\begin{array}{c}\text { Stress at break } \\
\mathrm{MPa}\end{array}$ & $\begin{array}{c}\text { Elongation \% } \\
\text { at break }\end{array}$ \\
\hline $\mathbf{1}$ & 24.1 & 13.3 & 19.4 & 420 \\
$\mathbf{2}$ & 25.2 & 15.6 & 20.7 & 540 \\
$\mathbf{3}$ & 27.3 & 17.1 & 24.1 & $>800$ \\
$\mathbf{4}$ & 31.8 & 19.3 & 27.1 & $>800$ \\
\hline
\end{tabular}

The obtained data regarding the mechanical properties of blank iPP and iPP/ HOCP blends can be investigated based on the mechanism of plastic deformation of semicrystalline polymers, namely the crystallographic slip. The Egypt. J. Rad. Sci. Applic., Vol. 24, No. 2 (2011) 
mechanism of the ctystallographic slip is based on the displacement of one block of crystal regarding another one in particular crystallographic plane. Such displacement is possible due to dislocation presence. Due to iPP modification with different molecular wt of HOCP resins will allow a distortion of crystal structure and therefore HOCP resin connected to iPP chain will be partially dissolved in the amorphous phase and partially trapped in polymer crystals. The dislocation in such conditions will be stabilized and therefore higher forces will be needed to start polymer deformation. Another possible reason for the increase of yield stress in the blend is the decrease of the number of movable dislocations of iPP crystals in the blends (Pluta et al., 2000).

\section{Dynamic mechanical analysis}

The dynamic mechanical properties (tan $\delta, \mathrm{E}^{\prime}$ and $\mathrm{E}$ " of iPP and iPP/ HOCP (80/ $20 \mathrm{wt} \%)$ samples as a function of temperature are displayed in Figure 2. The iPP curve showed three dynamic mechanical relaxation processes labelled as $\gamma$ (around $-50{ }^{\circ} \mathrm{C}$ ), $\beta$ (around $+15{ }^{\circ} \mathrm{C}$ ) and $\alpha$ (around $+60{ }^{\circ} \mathrm{C}$ ).

The $\gamma$-relaxation process was assigned to the local relaxation mode involving a few chain segment of amorphous phase. Also, this relaxation process is associated with the motion of methylene groups of the main chain in the amorphous regions. The $\beta$-relaxation process is associated with the branch points containing the side group. The $\beta$-relaxation process was usually attributed to the glass-rubber transition of the amorphous phase. Finally the $\gamma-$ relaxation process is believed to the vibrational-rotational motion within the crystalline zone. The $\gamma$-relaxation process is believed to be due to the vibrational or reorientation motions within the crystal (Sarkar et al., 1998).

The iPP/ HOCP blends exhibited a single broad peak with higher $\beta$-relaxation temperature at about $40-50{ }^{\circ} \mathrm{C}$ in the mechanical loss-temperature dependence relationship. It was found that the maximum of the $\beta$-relaxation transition peak for iPP/ HOCP blends shifted toward higher temperature and the shift is associated with the decrease of molecular wt of HOCP resin. The maximum value of $\tan \delta$ corresponding to the $\beta$-relaxation transition peak for iPP/ HOCP blends increased and reached its maximum for blend containing lower molecular wt HOCP resin. DMA regarding mechanical loss-temperature relationship for iPP/ HOCP blends are accounted by assuming that iPP and

Egypt. J. Rad. Sci. Applic., Vol. 24, No. 2 (2011) 
HOCP components were to some extent completely miscible of single broadened peak. The compatibility of iPP/ HOCP blends and also the degree of crosslinking increased with the decrease of molecular wt distribution values (Chattadhyay et al., 2002).

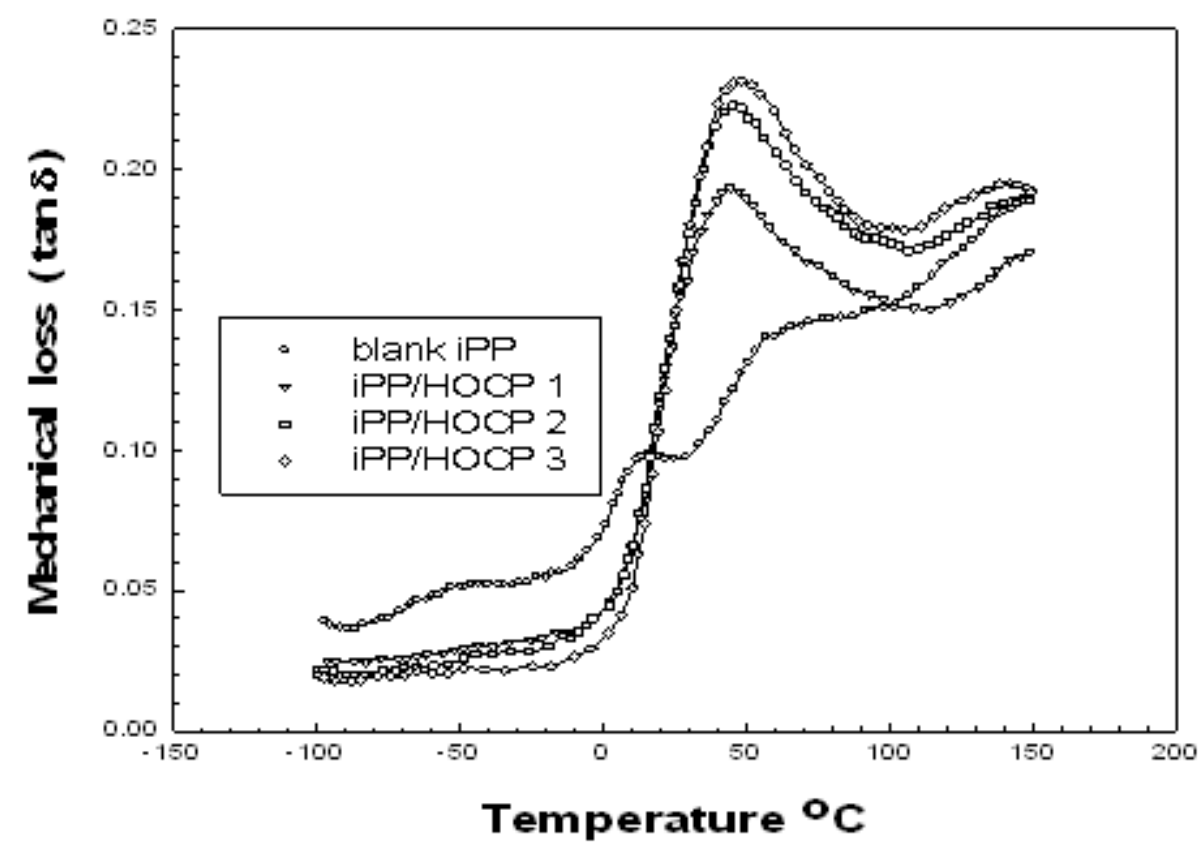

Fig. 2. Tan $\delta$ of blank blank iPP and iPP/ HOCP samples as a function of temperature.

The size and the broadening of the $\beta$-relaxation process for iPP/ HOCP blends is being to be of higher extent ( 2.5 times) as compared with that for blank iPP sample. One can deduced that iPP/ HOCP blends exhibited only one broad relaxation process ( $\beta$-relaxation transition peak) indicating the excellent compatibility between the blend components.

The change of E' for iPP and iPP/ HOCP blends over the temperature interval -100 to $+50{ }^{\circ} \mathrm{C}$ is shown in Fig. 3. At temperature below $0.0{ }^{\circ} \mathrm{C}$, both blank iPP and iPP/ HOCP samples exhibited similar behaviour, where the values of $\mathrm{E}^{\prime}$ slightly decreased by the same rate with increasing temperature from $-100{ }^{\circ} \mathrm{C}$ up to $0.0{ }^{\circ} \mathrm{C}$. Above $0.0{ }^{\circ} \mathrm{C}$ temperature, there is an abrupt change in the $\mathrm{E}^{\prime}$ values and one can observed that all curves intersected at a temperature of about $45{ }^{\circ} \mathrm{C}$. The temperature at which the abrupt change occurred is Egypt. J. Rad. Sci. Applic., Vol. 24, No. 2 (2011) 
considered to be the glass transition temperature of the glass rubber phase which was related to the $\beta$-relaxation transition peak (see Fig. 2).

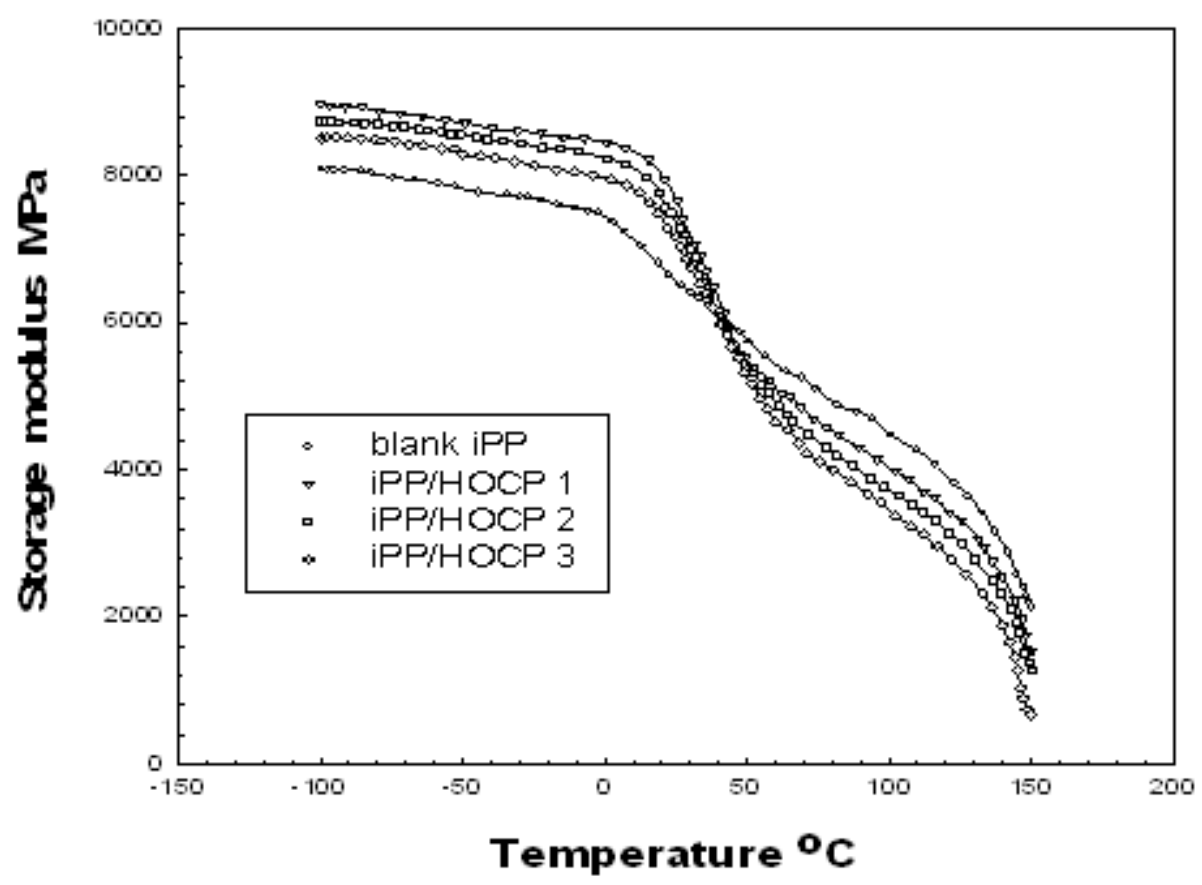

Fig. 3. Storage modulus of blank iPP and iPP/ HOCP samples as a function of temperature.

At temperature lower than $40-45^{\circ} \mathrm{C}$, the $\mathrm{E}^{\prime}$ values for iPP/ HOCP blends are higher than those for blank iPP sample, while at temperature higher than 45 ${ }^{\circ} \mathrm{C}$, the situation was reversed. In general, the decrease of $\mathrm{E}^{\prime}$ values for either iPP or iPP/ HOCP samples with increasing temperature is characterized of semicrystalline polymer and the diverse slopes of iPP and iPP/ HOCP samples are due to the fact that blank iPP matrix is more crystalline than those iPP/HOCP blends (Chattadhyay et al., 2002). This behaviour can be explained by assuming that when the amorphous phase of iPP/ HOCP blend is in the glassy phase, the presence of HOCP resin causes an increase of rigidity, while at higher temperature, where the amorphous phase is in the rubbery conditions, the HOCP acts as a plasticizer.

Fig. 4. depicted the change in the E" values for blank iPP and iPP/ HOCP (80/ $20 \mathrm{wt} \%$ ) samples as a function of temperature. The blank iPP sample Egypt. J. Rad. Sci. Applic., Vol. 24, No. 2 (2011) 
presented a single peak (onset temperature at about $-10{ }^{\circ} \mathrm{C}$ and endset temperature at about $+30{ }^{\circ} \mathrm{C}$ ) whose its maximum is centered at $+10{ }^{\circ} \mathrm{C}$. This peak corresponds to the $\mathrm{T}_{\mathrm{g}}$ of iPP. On the other hand, iPP/ HOCP blends showed also a single broad peak whose maxima are centred at higher temperatures in the range $25-30{ }^{\circ} \mathrm{C}$. As shown in Figure 4, the E" values for iPP/ HOCP blends increased as the molecular wt distribution values of HOCP resins decreased (Mendes et al., 1996).

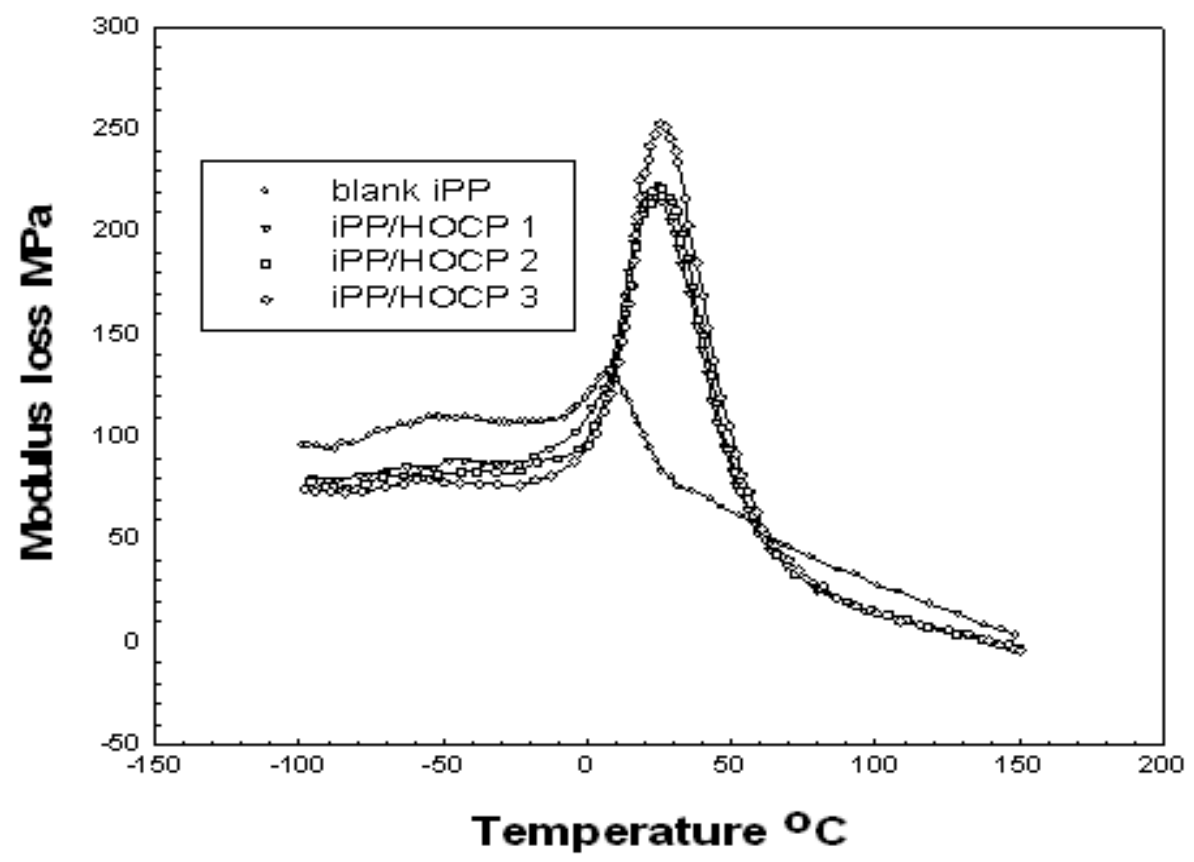

Fig. 4. Modulus loss blank iPP and iPP/ HOCP samples as a function of temperature.

The behaviours of $\tan \delta, E^{\prime}$ and $E^{\prime \prime}$ could be explained by considering that the semicrystalline iPP and the amorphous HOCP components are miscible in the temperature range of the DMA, $\left(-100\right.$ up to $\left.+150{ }^{\circ} \mathrm{C}\right)$, and that the $\mathrm{T}_{\mathrm{g}}$ of the iPP increased through the blending with different molecular wt HOCP resins. The differences in the dynamic mechanical response of blank iPP and iPP/HOCP samples should be ascribed primarily to the variation in the structure of HOCP component In addition, the pre-irradiation of blend components play an important role in enhancement the degree of crosslinking which in turn leads to the compatibility of blend components.

Egypt. J. Rad. Sci. Applic., Vol. 24, No. 2 (2011) 


\section{Scanning electron microscopic investigation (SEM)}

Under identical processing conditions, the relative proportion, molecular wt of the components and their difference in melt viscosity play a significant role in determining the morphology. If the individual components have similar melt viscosities; the resultant morphology of the blend is expected to be very fine, and a uniform distribution of the minor component into the major component becomes apparent. However, when the components have different melt viscosities, the morphology of the resulting blend depends on the whether the melt viscosity compared to the major one (Ray and Khastgir, 1993).

(a)

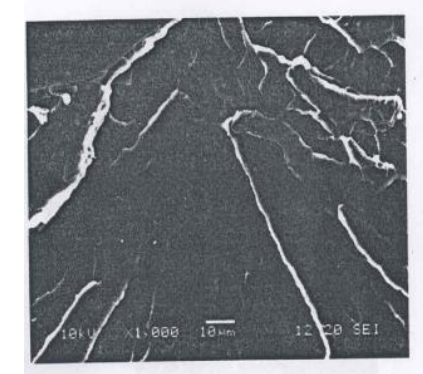

(c)

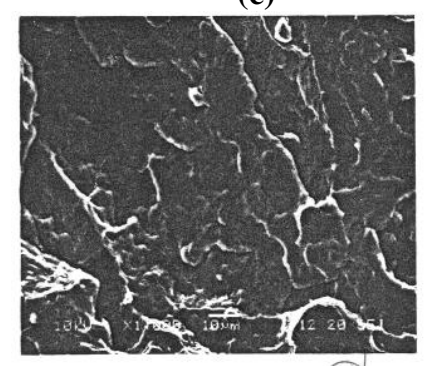

(b)

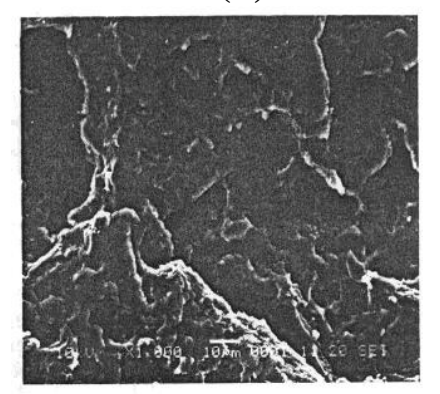

(d)

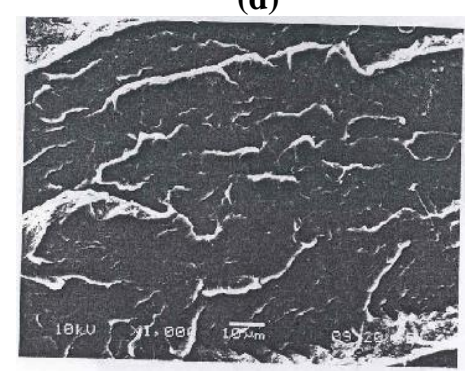

Fig. 5. Morphological structure of (a) blank iPP (b) iPP/ HOCP1 (c) iPP/ HOCP2 and (d) iPP/ HOCP3 samples.

The information on the miscibility of iPP/ HOCP blends was carried out using SEM technique. Electron micrographs of fracture surfaces of blank iPP and iPP/ HOCP samples were presented in Fig. 5. Blank iPP and iPP/ HOCP blends are sphereultic with dimension of about $10 \mu \mathrm{m}$ and some voids are present. For blank iPP sample (Figure 5a), the morphology did not show domains of disperse phase. On the other hand, the morphology of iPP/ HOCP blends depended largely on the physical and chemical properties of the HOCP resins. As shown Egypt. J. Rad. Sci. Applic., Vol. 24, No. 2 (2011) 
in Fig. 5 b, c, and d, the fracture surfaces of the investigated blends also did not show domains of dispersed phase, however, the slightly noticeable dispersed phase in the micrographs of some blends was connected with iPP matrix. For all iPP/ HOCP blends, no segregated domains in the matrix of iPP were observed, suggesting the miscibility between the blend components. The SEM micrographs of iPP/ HOCP blends were characterized by good dispersibility and good interfacial adhesion. Thereby, the influence of the chemical character of the HOCP resins, their melt viscosities and molecular weights on compatibility with iPP had been observed.

\section{Conclusion}

DSC investigation has shown that the $\mathrm{T}_{\mathrm{m}}, \Delta \mathrm{H}_{\mathrm{f}}$, the overall crystallinity was decreased by the presence of HOCP resin. This result, together with the detection of a single melting point, suggests that both pre-irradiated iPP and HOCP components are compatible in the melt. iPP/ HOCP blends showed superior mechanical behaviour compared to iPP. DMA results showed that blank iPP exhibited three dynamic mechanical $\gamma, \beta$ and $\alpha$ - relaxation processes, whereas iPP/ HOCP blends showed a broad peak related to the $\beta$-relaxation process. The E' values decreased with the increase of temperature and also with the decrease of molecular wt distribution of HOCP resins. A unique peak of the E" versus temperature was always presented indicating that the blends exhibited compatible system. The properties and the possible morphological features of iPP/ HOCP blends were confirmed to be compatible in the amorphous regions of the blend forming a homogenous amorphous phase.

\section{References}

Bonfatti, A. M., Canetti, M., Sadocco, P., Seves, A. and Martuscelli, E. (1993) Crystallization and thermal behaviour of isotactic polypropylene/ hydrogenated oligo (cyclopentadiene) blends. Polymer, 34, 990.

Cecere, A., Greco, R. and Taglialatila, A. (1992) Isotactic polypropylene/ hydrogenated oligo (cyclopentadiene) blends: 1 Thermal and dynamic-mechanical behaviour of annealed samples. Polymer, 33, 1411.

Chattopadhyay, S., Chaki, T. K. and Bhowmick, A. K. (2002) Development of new thermoplastic elastomers from blends of polyethylene and ethylene vinyl acetate copolymers by electron beam technology. J. Appl. Polym. Sci., 798, 1877.

Egypt. J. Rad. Sci. Applic., Vol. 24, No. 2 (2011) 
Ivanov, I., Muke, S., Kao, N. and Bhattacharya, S. N. (2001) Morphological and rheological study of polypropylene blends with a commercial modifier based on hydrogenated oligo (cyclopentadiene), Polymer, 42, 9809.

Mendes, L. C., Tavares, M. I. B. and Mano, E. B. (1996) Compatibility of iPP/HOCP binary blends by OM, DSC, DMTA, and ${ }^{13} \mathrm{C}$ nuclear magnetic resonance, Polym. Testing, 15, 53.

Pluta, M., Bartczak Z. and Galeski, A. (2000) Changes in themoepholgy and orientation of bulk spherulitic polypropylene due to plane strain compression, Polymer, 41, 2271.

Ray, I. and Khastgir, D. (1993) Corrlation between morphology with dynamic mechanical thermal, physicochemical propertyies and electrical conductivity for EVA-LDPE blends. Polymer, 34, 2037.

Sarkar, M. D., De, P. P. and Bhowmick, A. K. (1998) New polymeric blends from hydrogenated styrene-butadiene rubber and polyethylene. Polymer, 39, 6789.

Silvestre, C., Cimmino, S. and Pirozzi, B. (2003) Morphology of a melt crystallized iPP/HDPE/hydrogenated hydrocarbon resin blend. Polymer, 44, 4273.

Slivestre, C., Cimmino, S., Alma, E. D., Di Lorenzo, M. L. and Di Pace, E. (1999) Crystallization of isotactic polypropylene/natural terpene resins blends. Polymer, 40, 5119.

Triolo, A., Lin, J. S., Wignall, G. D. and Triolo, R. (2000) Structure of isotactic polypropylene-hydrogenated oligo (cyclopentadiene), (iPP-HOCP) blends Part II, HOCP-rich blends. Polymer, 41, 3751.

Triolo, A., Silvestre, C., Cimmino, S., Martuscelli, E., Caponetti, E. and Triolo, R. (1998) Structure of isotactic polypropylene/hydrogenated oligo (cyclopentadiene) blends: 2 Polypropylrnr-rich blends. Polymer, 39, 1697.

(Received: 17/04/2012;

accepted: 17/05/2012)

Egypt. J. Rad. Sci. Applic., Vol. 24, No. 2 (2011) 


$$
\begin{aligned}
& \text { توصـيف توليفـات الايزوتاكتيـك بـولى بـروبيلين و الاوليجـو } \\
& \text { سيكلو بنتادايين المهدرج تولينات الايزو }
\end{aligned}
$$

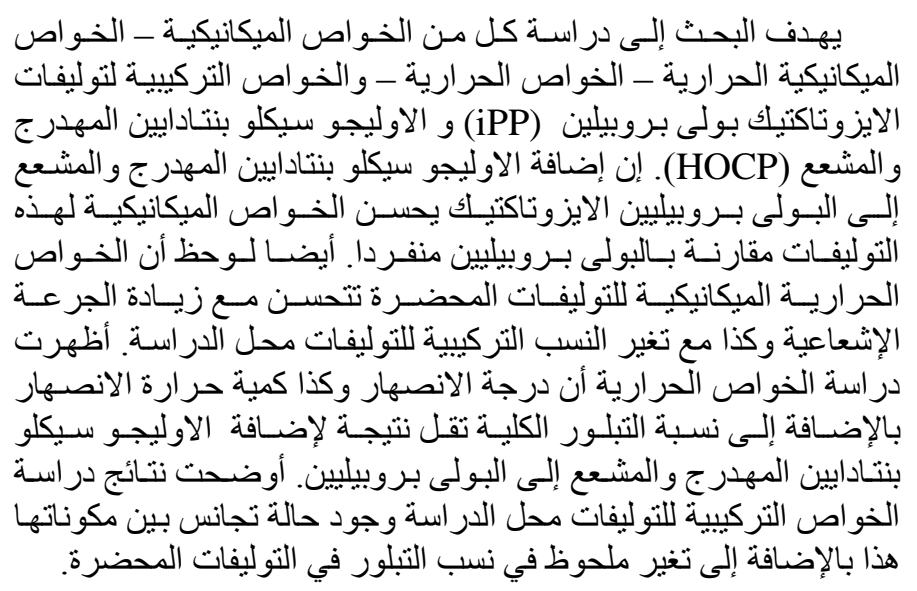

Egypt. J. Rad. Sci. Applic., Vol. 24, No. 2 (2011) 